\title{
The Question of Purpose
}

\author{
David Zeigler
}

Published online: 20 November 2007

(C) Springer Science + Business Media, LLC 2007

Keywords Evolution · Purpose · Progressionism · Teleology

The rational world is not teleological in the old sense. It certainly has purpose, but the purposes are not imposed from without or anticipatory of the future. They are internal to each species separately.

\section{(George Gaylord Simpson. This View of Life)}

There is no known genetic mechanism that could produce goal-directed evolutionary processes.

(Ernst Mayr. What Evolution Is)

In his monumental work Novum Organum (1620), Francis Bacon wrote "The human understanding on account of its own nature readily supposes a greater order and uniformity in things than it finds." This statement so obviously applies to a number of human follies. It could be applied to belief systems like astrology in which the movements and "order" of the heavenly bodies are said to have a strong and systematic influence on the lives of us meager humans (a premise totally unfounded in science). It applies to the millions who, over the centuries, "perceived" an unfolding "order" in the events of history or in their individual lives (fate, destiny, or God's plan for one's life). Bacon's statement points to our myriad attempts to find and understand the "meaning" behind the order we do find in the universe, the order that allows science to exist but which, if taken to unobjective extremes, can produce the follies of astrology, numerology, evolutionary progressionism,

D. Zeigler $(\bowtie)$

The University of North Carolina at Pembroke,

Pembroke, NC, USA

e-mail: david.zeigler@uncp.edu and a host of other belief systems. More recently, the great evolutionist John Maynard Smith wrote in a similar vein “... human beings find it difficult to accept any input as meaningless. Shown an inkblot, we see witches, bats, and dragons." (Natural History 11/84).

Around Bacon's time, Shakespeare expressed an opposing sentiment in his great tragedy Macbeth with the line "it [life] is a tale told by an idiot, full of sound and fury, signifying nothing," which echoes more recently in Steven Weinberg's line from The First Three Minutes (1977) - "The more the universe seems comprehensible, the more it also seems pointless." Because we stumbled in our evolution onto what is referred to as "full consciousness," we tend to see our individual lives as significant and important; we see them as containing a past - and a future for which we may plan. We also acquired the knowledge that we would die sometime in this future. In short, our life was a story with a past and future, and perhaps we hoped-even a future beyond "earthly death." We seem predisposed to assume that there is meaning behind the events unfolding around us (including our evolution), and for most humans meaning transforms readily into purpose. I could quote many other modern scientists who reject the notion of purpose in the universe, of which life and evolution are for us a significant part. If you have read much of Stephen J. Gould, you know that many of his writings, especially his Full House, are lucid arguments for this point of view.

My "purpose" (we can create our own temporally and spatially limited purposes) in writing this piece is to point out one of the most important and real issues in the teaching of Darwinian evolution that so often goes unaddressed, or more amazingly - unrecognized, and this issue is really fairly obvious. Darwinian evolution by natural selection results in adaptations which increase the ability of the individuals to survive and reproduce success- 
fully in their respective environments, or as biologists would say - adaptations increase the fitness of individuals. This is the only evolutionary goal or purpose for which science has found objective evidence.

In our science, there is no mention of, or mechanism for achieving, any long-term metaphysical or teological goals of form, complexity, or intelligence - as Gould has argued so eloquently. Most of the other known mechanisms of evolutionary change such as genetic drift, neutral mutation, gene duplications, transposons, horizontal gene transfer by plasmids, and others have no direction or goal at all and are in fact random (which natural selection is not) and therefore could not possibly give a particular direction to evolution. Numerous science writers have made the obvious point that had that asteroid not struck some $65,000,000$ years ago and pushed the dinosaurs to extinction, we humans would undoubtedly not be here, for the evolution of mammals would have been constrained and altered drastically from what has come to pass (i.e., we humans were not destined to evolve).

If we teach evolution honestly, we cannot really avoid this point, although many succeed in doing so. Additionally, if we give any credence to some hybrid form of teleological evolution by which humans or any of the socalled "higher" forms were destined to appear, we have gutted Darwinian evolution of its scientific core and replaced it with an unfounded belief - one that too many of our students (and most intelligent design proponents) already hold. I believe it is in part because we tiptoe around the honest interpretation of Darwinism that the USA lags far behind the other developed countries of the world in accepting the modern scientific view of evolution and in taking a realistic view of our precarious place (and responsibilities) on this fragile planet.

Taken as a whole, the evolution of life is not a story of progress but rather one of success of the very few and failure of the many (not all were failures in the sense of being unfit because no matter how well-adapted the species - most did not survive the catastrophic events of the five major extinction events, the asteriod at the end of the Cretaceous being the last. Over $99 \%$ of all the species that have ever lived are now extinct, and the vast majority of spores, seeds, eggs, hatchlings, newborns, etc. never make it to reproductive adulthood. Every species alive today is a huge success story. To paraphrase Lynn Margulis-all species alive today have survived over 3,000,000,000 years of evolution from common bacterial ancestors, and all are equally evolved (Symbiotic Planet, 1998). Darwin saw natural selection for what it is, a strong weeding-out process whereby populations adapt to be successful in their local environments - and nothing more (and yes, there is a large element of "luck" as well-as in the asteroid event). There is no force or direction toward any particular goal in the evolutionary process, unless you allow that successful survival and reproduction in your local environment constitutes that goal.

This is the truth science has revealed. Do we teach it as such? I have no new ideas on how best to teach this truth, but it cannot really be avoided if one is to teach evolution as scientists currently understand it. When I cover evolution (university level-but Bible belt region), I teach it unapologetically from the freshman level through the senior level, and several of my students have thanked me for this matter-of-fact approach to evolution. I decided to enter science because I came to view it as the only discipline in which one could find real objective truth, the only view which could inform one as to the true nature of reality. I would hope that many (although undoubtedly not all) students still hunger for the same thing.

In the now-classic science fiction movie The Matrix, the hero Neo is confronted by Morpheus and offered the ability to see the truth about what is, and what is not, real. All Neo has to do is to take the red pill and he will learn that the reality he thought he knew and understood was but a myth-literally in his case a virtual reality. Neo of course chooses to discover the truth. In a very real sense, the vast human-centered worldview to which most people cling is also a virtual reality - one of our own making and one which shields us from many of the important and awesome truths science has revealed concerning the universe we inhabit - but truths which for many are alien, cold, and uncomforting. The universe shows itself to the scientist as obviously not "about us" but one in which people who understand reality have the responsibility to make important decisions, not only about how to teach the next generation but also about how to preserve our planet and the awesome biodiversity we share it with. Especially because of biodiversity (the product of evolution) there is indeed "grandeur in this view of life." 